\title{
Introduction
}

\section{Pierre Ralle}

\section{(2) OpenEdition}

\section{Journals}

Édition électronique

URL : http://journals.openedition.org/travailemploi/4161

DOI : 10.4000/travailemploi.4161

ISSN : 1775-416X

Éditeur

DARES - Ministère du Travail

\section{Édition imprimée}

Date de publication : 5 juin 2009

Pagination : 11

ISSN : 0224-4365

\section{Référence électronique}

Pierre Ralle, «Introduction », Travail et Emploi [En ligne], 118 | avril-juin 2009, mis en ligne le 05 novembre 2010, consulté le 22 septembre 2020. URL : http://journals.openedition.org/travailemploi/ 4161 ; DOI : https://doi.org/10.4000/travailemploi.4161 


\section{Introduction}

En 1994, après plusieurs décennies d'augmentation du chômage et dans une conjoncture économique plutôt médiocre, l'OCDE rassemblait un certain nombre de travaux qu'elle avait réalisés et de recommandations de politique économique dans un ouvrage intitulé Étude de l'OCDE sur l'emploi. Ce document a été perçu dans les années qui suivirent comme la «ligne de l'OCDE» en ce qui concerne l'emploi. L'adaptation des économies à leur environnement et la flexibilité des marchés, et en particulier celui du travail, étaient les composantes essentielles des politiques prônées.

Une dizaine d'années plus tard, alors que le taux de chômage avait baissé de plusieurs points, l'OCDE a jugé utile de tirer les enseignements de ces premières recommandations et de prendre en compte les avancées de la connaissance économique : 1'OCDE a ainsi réalisé un exercice du même style, s'appuyant sur les travaux théoriques et empiriques les plus récents, et a abouti à de nouvelles recommandations. Celles-ci ont donné lieu à la publication d'un ouvrage «réévaluant la stratégie de l'OCDE pour l'emploi», publié dans les Perspectives de l'emploi de l'OCDE de 2006. Une présentation de cette nouvelle stratégie de l'OCDE pour l'emploi ainsi qu'une synthèse des quatre grandes lignes d'action proposées par 1'OCDE en 2006 figurent dans l'article de John P. Martin qui introduit ce numéro spécial de Travail et Emploi.

Ces travaux ont donné lieu à un colloque, organisé à Paris par la DARES, en partenariat avec l'OCDE, fin 2006 et consacré aux enseignements à en tirer pour la France. Au cours de ce colloque, une vingtaine d'économistes de renommée mondiale présentèrent leur contribution à l'analyse du cas français. Ils s'adressaient à un large public, composé de chercheurs, d'étudiants, de cadres ayant en charge la politique de l'emploi, d'acteurs économiques et sociaux. De ces contributions, retravaillées par la suite, sont issus les seize articles de ce numéro spécial de Travail et Emploi (1). S'appuyant, sur les travaux de l'OCDE, les auteurs apportent leur diagnostic sur la situation de la France, telle qu'elle pouvait apparaître en 2006. Approuvant, nuançant ou critiquant les conclusions de l'OCDE, ils dressent un état des lieux précis et rigoureux de l'économie française et de son marché du travail avant la crise actuelle. La publication de ce numéro permettra aux lecteurs de Travail et Emploi de bénéficier de ces analyses passionnantes et sans concession.

Pierre Ralle

Rédacteur en chef

(1) Les articles de ce numéro n'ont pas été soumis à des relecteurs anonymes. 